\title{
Laser-Induced Point Defects in Fused Silica Irradiated by UV Laser in Vacuum
}

\author{
Xiaoyan Zhou, Xinda Zhou, Jin Huang, Qiang Cheng, Fengrui Wang, \\ Xin Ye, Xiaodong Jiang, and Weidong Wu \\ Research Center of Laser Fusion, China Academy of Engineering Physics, Mianyang 621900, China \\ Correspondence should be addressed to Weidong Wu; wuweidongding@163.com
}

Received 27 February 2014; Revised 8 June 2014; Accepted 25 July 2014; Published 17 August 2014

Academic Editor: Wanguo Zheng

Copyright (c) 2014 Xiaoyan Zhou et al. This is an open access article distributed under the Creative Commons Attribution License, which permits unrestricted use, distribution, and reproduction in any medium, provided the original work is properly cited.

High-purity fused silica irradiated by third harmonic of the Nd:YAG laser in vacuum with different laser pulse parameters was studied experimentally. Laser-induced defects are investigated by UV spectroscopy, and fluorescence spectra and correlated to the structural modifications in the glass matrix through Raman spectroscopy. Results show that, for laser fluence below laser-induced damage threshold (LIDT), the absorbance and intensity of fluorescence bands increase with laser energies and/or number of laser pulses, which indicates that laser-induced defects are enhanced by laser energies and/or number of laser pulses in vacuum. The optical properties of these point defects were discussed in detail.

\section{Introduction}

Fused silica has excellent ultraviolet (UV, $\lambda \leqq 400 \mathrm{~nm}$ ) transparency, optical homogeneity, and high antidamage performance in UV pulse laser $[1,2]$. This optical property allows this material to be used in optical materials for large high power output systems such as Laser Megajoule and National Ignition Facility $[3,4]$. However, UV optical properties of fused silica are often degraded by preexisting and laserinduced point defects, since they induce optical absorption and fluctuation of the refractive index [5]. Moreover, the concentration of laser-induced defects can be increased by laser irradiation, and light absorption caused by laserinduced defects may further produce laser-induced damage [6-8]. Hence, elucidating the nature of light absorption and fluorescence of point defects in the laser modified fused silica is important for controlling the evolution of laser damage and designing an effective damage mitigation procedure in excimer laser applications and power solid laser facility [9].

Defects induced in fused silica in atmospheric air have been widely investigated [10-12]. For many practical applications, a vacuum environment is necessary. In recent years, laser-induced defects in fused silica under high power UV irradiation have aroused considerable interest [13-16]. However, relatively low laser fluence but large number of shots is the most commonly used situation for fused silica optics. Low fluence laser may induce transmission loss, unacceptable refractive index change, and surface roughing in fused silica $[17,18]$. Besides, characterization of material modifications induced by low fluence laser provides a physical basis for understanding the laser damage mechanism. In this paper, we attempted to characterize the point defects in fused silica induced by low fluence laser $(355 \mathrm{~nm}$ Nd:YAG laser pulses) with different laser pulse parameters in vacuum. Laser-induced point defects were characterized by UV-vis, fluorescence, and Raman spectra. The formations of point defects before and during the laser-induced material damage were also discussed in detail.

\section{Experiment Procedures}

Optically polished high-purity fused silica specimens (Corning 7980) were specially monitored during preparation to ensure no defects were introduced. In the experiment, fused silica $\left(25 \times 25 \times 3 \mathrm{~mm}^{3}\right)$ was mounted on an electromotion manipulator in the vacuum chamber. Prior to laser irradiation, all samples were thoroughly cleaned in order to prevent external contamination on studied surfaces, which could interact with the excitation radiation. The vacuum chamber was evacuated to a base pressure of $10^{-2} \mathrm{~Pa}$. Fused silica was 
irradiated by $355 \mathrm{~nm}$ beam from a frequency tripled Nd-YAG laser. The pulse length (full width at half maximum) was $9.3 \mathrm{~ns}$ and laser repetition rate was $1 \mathrm{~Hz}$. Fluence fluctuations have a standard deviation of about $\pm 4.5 \%$ at $355 \mathrm{~nm}$. During the test, the beam is focused on the sample surface in order to achieve high fluence. The modulation of irradiated area is a factor of 2.5. During damage threshold testing, laser beam was focused on $7 \mathrm{~mm}^{2}$ at the sample plane. Typical R-on-1 laser damage test was performed on untreated fused silica surface in air and vacuum, and the fluence gradually ramps up to the damaging fluence. The damage of fused silica is always ignited at the maximum of the beam fluence. An image of the irradiated zone is acquired by a digital microscope before and after each shot in order to observe the surface of fused silica. The point defects were produced exclusively on the exit surface of the optics using multiple pulses with fluence ranging from 4 to $12 \mathrm{~J} / \mathrm{cm}^{2}$, which was below the laserinduced damage threshold. The damage crater on fused silica was irradiated by the fluence $\left(11.6 \mathrm{~J} / \mathrm{cm}^{2}\right)$ below laser-induced damage threshold (LIDT) with multiple pulses.

Fluorescence spectra were measured by fluorescence spectrometer (FLS900, Edinburgh) furnished with a photomultiplier used as a detector and a Xe lamp used as an excitation source (emitting in the wavelength range from $265 \mathrm{~nm}$ to $500 \mathrm{~nm}$ ). Luminescence measurements were performed with a single-grating spectrograph. UV-vis spectra were measured by Lambda 950 (PerkinElmer) spectrophotometer, and the absorbance of sample is relative value. Laser Raman spectra of fused silica were obtained using a Horiba Jobin Yvon Xplora confocal spectrometer. All these spectra were measured at three different positions on the sample and the scatter in the intensity of bands due to position was less than $5 \%$.

\section{Results and Discussion}

3.1. Damage Threshold. In order to understand the effect of vacuum on the damage threshold, the damage performance of fused silica in air and vacuum $\left(10^{-2} \mathrm{~Pa}\right)$ was measured by R:1 test method. The result showed that damage thresholds were $19.3 \mathrm{~J} / \mathrm{cm}^{2}$ (in air) and $16.4 \mathrm{~J} / \mathrm{cm}^{2}$ (in vacuum), respectively. Compared with the damage threshold of fused silica optics measured in vacuum and air, laser-induced damage threshold of fused silica was slightly decreased in vacuum, which implies that vacuum can degrade the damage performance of fused silica. We presume that vacuum may accelerate the generation process of laser-induced point defects on fused silica.

3.2. Absorption Spectra. The absorption spectrum is frequently used to analyze the internal structure of fused silica [19]. In order to characterize the point defects induced by $355 \mathrm{~nm}$ laser pulses in vacuum $\left(10^{-2} \mathrm{~Pa}\right)$, we measured the absorption spectra of original and preirradiated fused silica. As shown in Figure 1, there are no obvious absorptions between $190 \mathrm{~nm}$ and $800 \mathrm{~nm}$ on the original fused silica. We can conclude that the preexisting defects are negligible to be the precursors inducing the absorption. After laser irradiation, a weak absorption band around $610 \mathrm{~nm}(2.0 \mathrm{eV})$

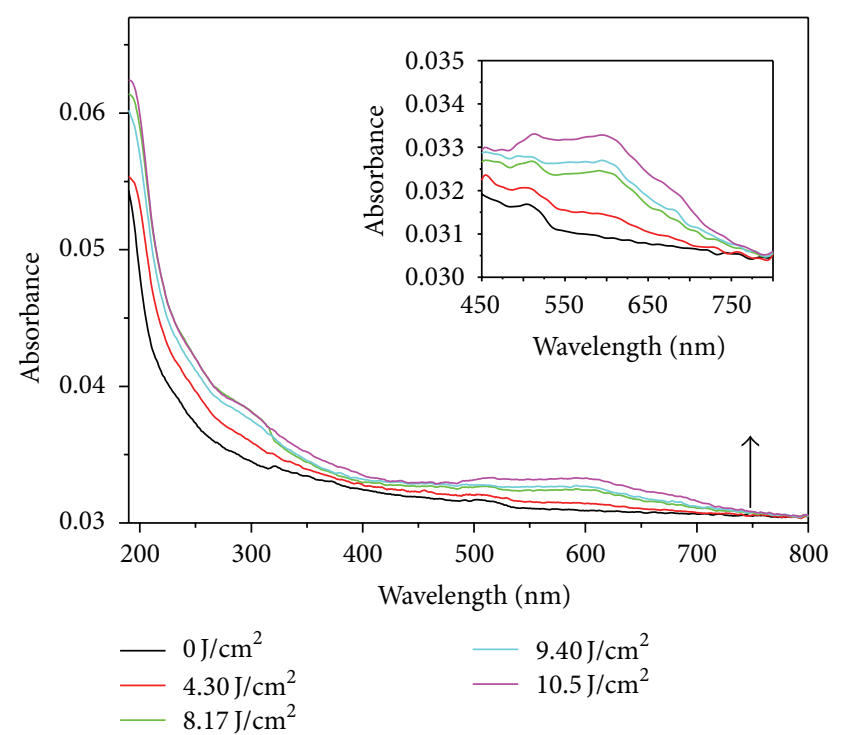

FIGURE 1: Absorption spectra of fused silica preirradiated in vacuum with 100 pulses at different laser pulse energies $\left(0 \mathrm{~J} / \mathrm{cm}^{2}, 4.3 \mathrm{~J} / \mathrm{cm}^{2}\right.$, $8.17 \mathrm{~J} / \mathrm{cm}^{2}, 9.40 \mathrm{~J} / \mathrm{cm}^{2}$, and $10.5 \mathrm{~J} / \mathrm{cm}^{2}$ ). The sample exhibits absorption between $500 \mathrm{~nm}$ and $700 \mathrm{~nm}$.

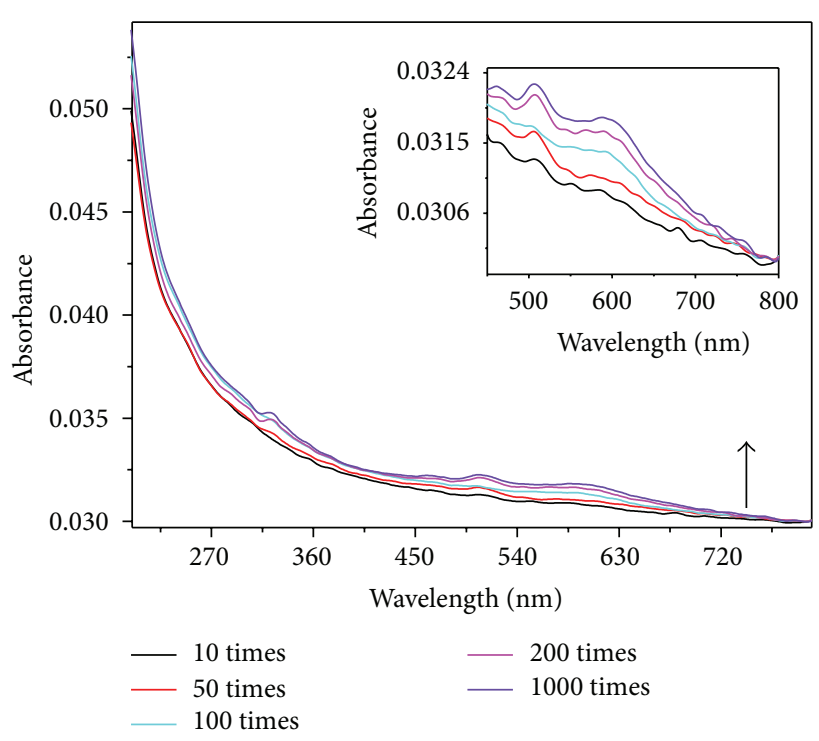

FIGURE 2: Absorption spectra of fused silica preirradiated in vacuum by different laser pulses numbers $(10,50,100,200$, and 1000); the pulse fluence is $8.16 \mathrm{~J} / \mathrm{cm}^{2}$. The sample exhibits a broad absorption between $500 \mathrm{~nm}$ and $700 \mathrm{~nm}$.

is observed [20], and the absorbance centered at $610 \mathrm{~nm}$ increases with the increasing pulse fluences. UV-vis spectra of sample irradiated in vacuum $\left(10^{-2} \mathrm{~Pa}\right)$ at the modest laser pulse fluence $\left(8.17 \mathrm{~J} / \mathrm{cm}^{2}\right)$ with different pulse numbers were also detected. From Figure 2, we can see that the observed absorbance $(610 \mathrm{~nm})$ is increasing with pulse numbers $(0-$ 200 pulses). The saturation behavior of the absorbance after 200 pulses reveals that pulse numbers only can break the strained bonds or dangling bonds of fused silica (Figure 3). 


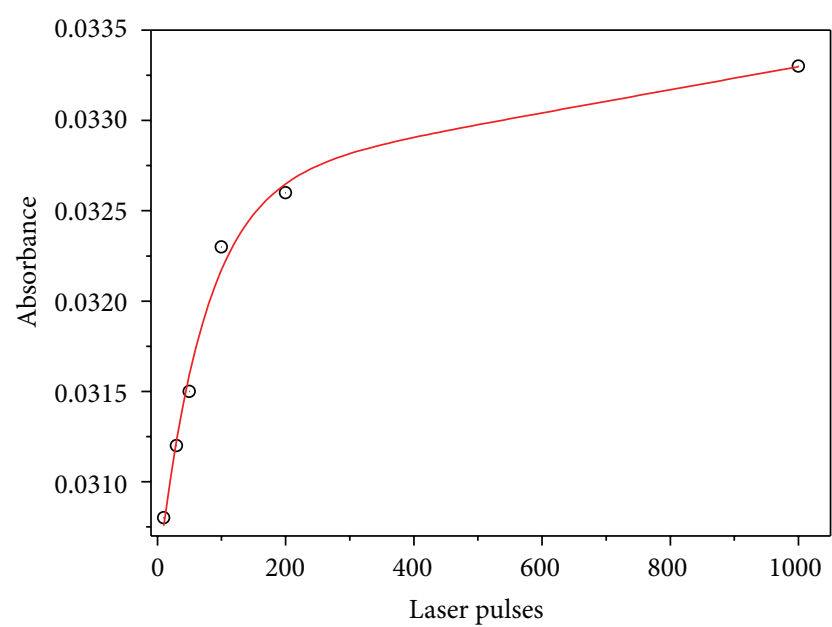

FIGURE 3: Various absorbances of the sample around $610 \mathrm{~nm}(2.0 \mathrm{eV})$ irradiated by different pulse numbers in vacuum; the pulse energy is $8.16 \mathrm{~J} / \mathrm{cm}^{2}$.

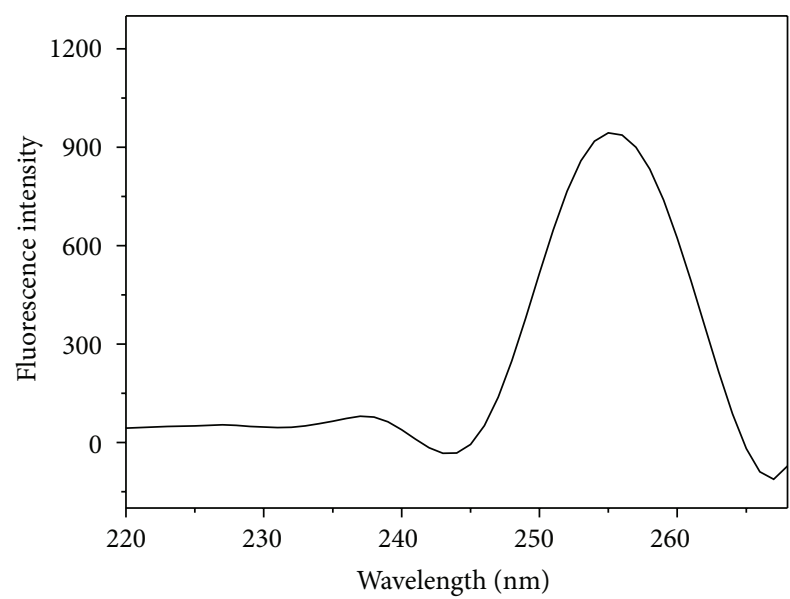

FIGURE 4: Fluorescence excitation spectrum of fused silica irradiated in vacuum; the pulse fluence is $8.16 \mathrm{~J} / \mathrm{cm}^{2}$.

The $2.0 \mathrm{eV}(610 \mathrm{~nm})$ band has been established to be nonbridging oxygen hole centers (NBOHC). In our experiment, the strained $\mathrm{Si}-\mathrm{O}-\mathrm{Si}$ bond and $\mathrm{SiOH}$ are the main precursors of NBOHC center [21, 22]. The oxygen-deficient defect (ODC) can give rise to absorption band centered at $250 \mathrm{~nm}(5.0 \mathrm{eV})$, which cannot be observed in the absorption spectra. A probable reason is that the absorbance of ODC is weak, and it cannot be detected by UV spectrophotometer.

Compared with these two absorption spectra (Figures 1 and 2), we can see that laser power has more effect on the formation and increasing of point defects than the numbers of laser pulses. In fused silica, the stability of total glass network cannot be considered only with the change of single bond energy. A strain of one bond will influence the structural stability of glass network in a certain area. The irradiation energy should be larger than the bond energy and then can accelerate the drastic bond breaking and defect formation. Low laser fluence with large number of shorts

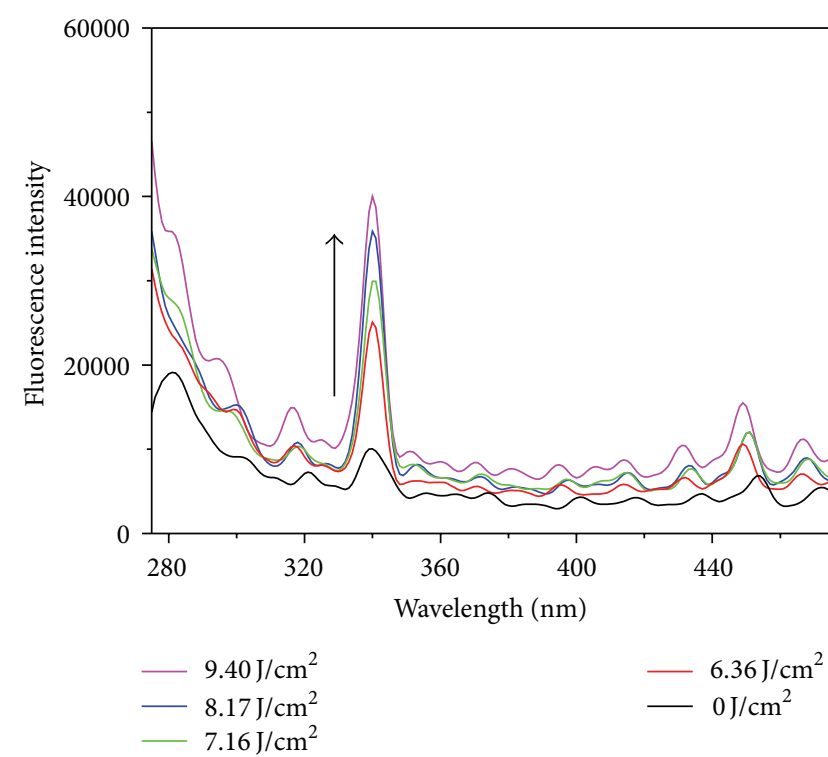

FIGURE 5: Fluorescence emission spectra of fused silica preirradiated in vacuum with 100 pulses at different laser pulse energies $\left(0 \mathrm{~J} / \mathrm{cm}^{2}\right.$, $6.36 \mathrm{~J} / \mathrm{cm}^{2}, 7.16 \mathrm{~J} / \mathrm{cm}^{2}, 8.17 \mathrm{~J} / \mathrm{cm}^{2}$, and $\left.9.40 \mathrm{~J} / \mathrm{cm}^{2}\right) ; \lambda_{\mathrm{ex}}=256 \mathrm{~nm}$.

only can break the dangle bonds or some strained bonds. However, the larger laser fluence can break the normal silica oxygen bonds to generate point defects. Increases in laser power and/or number of laser pulses enhance the absorbance of the sample, which is consistent with increases in the concentration of associated defects, and it was further confirmed by fluorescence spectra.

3.3. Fluorescence Spectra. Laser-induced fluorescence of fused silica following UV laser pulses is examined. In our experiment, the emission spectra were excited, centered at $256 \mathrm{~nm}(4.8 \mathrm{eV})$, as it is the case for ODC [23]. The excitation spectrum of fused silica can be seen from Figure 4, which is modulated by emission band around $335 \mathrm{~nm}$. The fluorescence emission spectra of fused silica irradiated in vacuum $\left(10^{-2} \mathrm{~Pa}\right)$ at different laser pulse fluence (100 pulses) are shown in Figure 5. The intensities of these emission bands increase after laser irradiation below LIDT. Moreover, fluorescence spectra of sample irradiated by laser pulses energy $\left(8.17 \mathrm{~J} / \mathrm{cm}^{2}\right)$ with different pulse numbers are shown in Figure 6 . The observed intensity at $335 \mathrm{~nm}$ increases with the pulse number from 10 to 200 . The saturation behavior of the fluorescence intensity after 200 pulses is consistent with the absorption spectra (Figure 6, inset). These results confirmed that increase in laser power and/or number of laser pulses could accelerate the formation process of associated defects in vacuum.

The fluorescence emission bands are related to a variety of known fundamental defects [24]. $459 \mathrm{~nm}(2.7 \mathrm{eV})$ and $282 \mathrm{~nm}(4.4 \mathrm{eV})$ emissions are attributed to oxygen-deficient defects (ODC), which have a corresponding absorption band around $5.0 \mathrm{eV}$ [25]. UV irradiation has a chance to break apparently strained or normal silicon-oxygen bonds. Thus, the formation of ODC (Figures 5 and 6) is attributed to the 


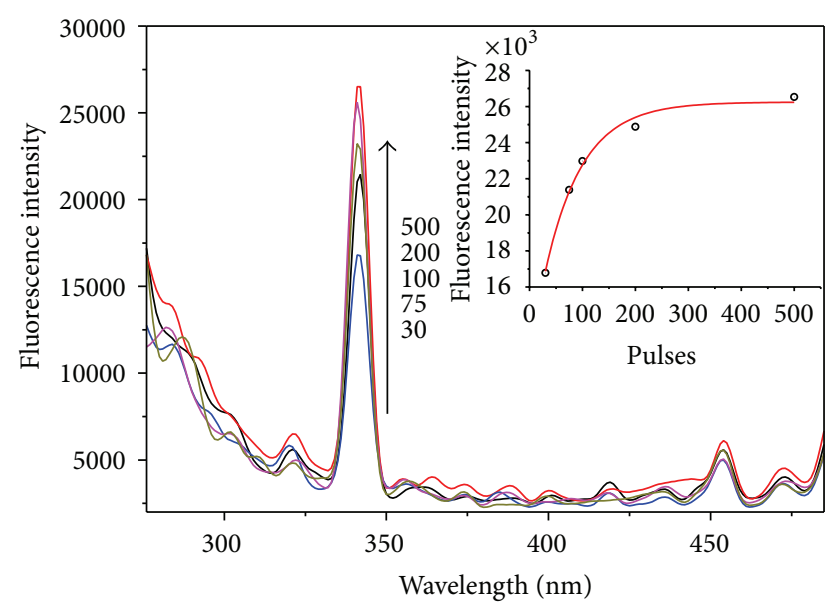

FIGURE 6: Fluorescence emission spectra of fused silica preirradiated in vacuum by different UV laser pulse numbers $(30,75,100,200$, and 500 ); the pulse fluence is $8.16 \mathrm{~J} / \mathrm{cm}^{2}$. Various fluorescence intensity at $335 \mathrm{~nm}$ irradiated by different pulse numbers in vacuum.

oxygen diffuse out of silicon-oxygen bonds. The band around $335 \mathrm{~nm}(3.7 \mathrm{eV})$ could not be clearly identified to date. Only a few publications have reported such an emission band in $\mathrm{Si}-\mathrm{SiO}_{2}$ nanoclusters and in porous silica, which were related to the singlet-singlet luminescence $\left(S_{0} \rightarrow S_{1}\right)$ of different kinds of ODCs [26]. In fluorescence spectra, we did not observe the typical emission band of NBOHC center centered at $650 \mathrm{~nm}(1.90 \mathrm{eV})$, which was restricted by the fluorescence spectrometer we used.

The emission spectra of the damage crater (beside and inside) were also detected. The damage crater on fused silica was irradiated by the fluence $\left(11.6 \mathrm{~J} / \mathrm{cm}^{2}\right)$ with pulses numbers of about 200. Laser-induced defects can lead to excessive absorption of the propagation laser light, which generates localized high energy deposition. Rapid material heating and associated thermal expansion result in stress fields, generating shock waves which may cause cracks or microexplosions. In addition, it should be noted here that the laser-induced damage is not observed at low power densities because the laser-induced defects concentration and energy deposition in the irradiated sample are low. In the damage crater of fused silica, three regions including damage edge, damage area, and damage core were measured by fluorescence spectra; the fluorescence beam is about $2 \mathrm{~mm}^{2}$. The damage core is centered in the damage crater. As can be seen from Figure 7, there is a new emission band around $395 \mathrm{~nm}(3.1 \mathrm{eV})$ in the laser-induced damage crater; the intensity of $395 \mathrm{~nm}$ band increases when the detect region is close to laser-induced damage core. However, there are some interesting phenomena; the intensity of $335 \mathrm{~nm}$ decreases in company with intensity of $395 \mathrm{~nm}$ increasing. In the damage core, the intensities of these two emission bands (335 and $395 \mathrm{~nm}$ ) are both the highest. It implies that point defects which are induced by laser below the damage threshold were influenced by the origin of laser-induced compaction, and they are enhanced by UV laser irradiation. The formation of

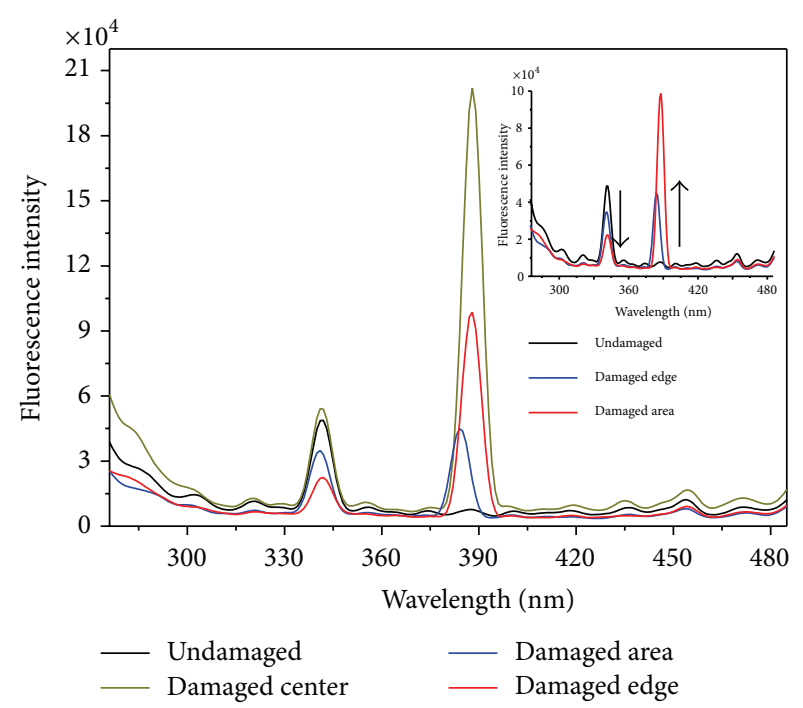

FIGURE 7: Fluorescence emission spectra of laser damage crater for different areas (undamaged, damaged edge, damage area, and damage core); $\lambda_{\text {ex }}=256 \mathrm{~nm}$.

point defects during the laser-induced damage was mainly responsible for physical processes.

The $395 \mathrm{~nm}(3.1 \mathrm{eV})$ band, subject to controversy, may have several distinct origins. It has first been proposed to be ODC defect built upon a Ge rather than a Si atom, yielding a $3.1 \mathrm{eV}$ band [27]. In our experiments, the involvement of germanium can be dismissed because no Ge has been detected in Corning 7980. Other hypotheses have been reported elsewhere, such as the presence of $\mathrm{Al}_{2} \mathrm{O}_{3}$ near the surface due to the polishing process $[21,22,28]$. However, it is believed that the involvement of $\mathrm{Al}_{2} \mathrm{O}_{3}$ polishing residues should be ruled out, mainly due to the very strong difference in luminescence intensity between flaws and pristine areas. However, there are few reports of the FL band near $3.1 \mathrm{eV}$ in undoped oxygen-deficient silica glass [29]. If the observed $3.1 \mathrm{eV}$ PL bands are not associated with impurities, it is possible that they are associated with unknown oxygendeficient-associated defect centers. Overall, the experimental data suggest that the luminescence bands at $3.1 \mathrm{eV}$ in the spectra of sample can be attributed to the oxygen-deficient centers [30], which are found to be higher in ablation spot than in original sample [31].

3.4. Raman Spectroscopy. Raman spectroscopy has proven to be an efficient method to characterize the structural modification in fused silica [32-36]. According to previous studies, with laser energy increasing, the change of amplitude of the $D_{1}$ and $D_{2}$ defect peaks can be observed in Raman spectroscopy. However, in our experiment, we did not observe obvious changes with different laser power and/or number of laser pulses. So the photoinduced structural changes in the preirradiated sample in vacuum at different areas (original and damaged area) were studied using Raman spectroscopy (Figure 8). The optical micrograph of the damage sample was shown in Figure 9. These Raman spectra consist of 


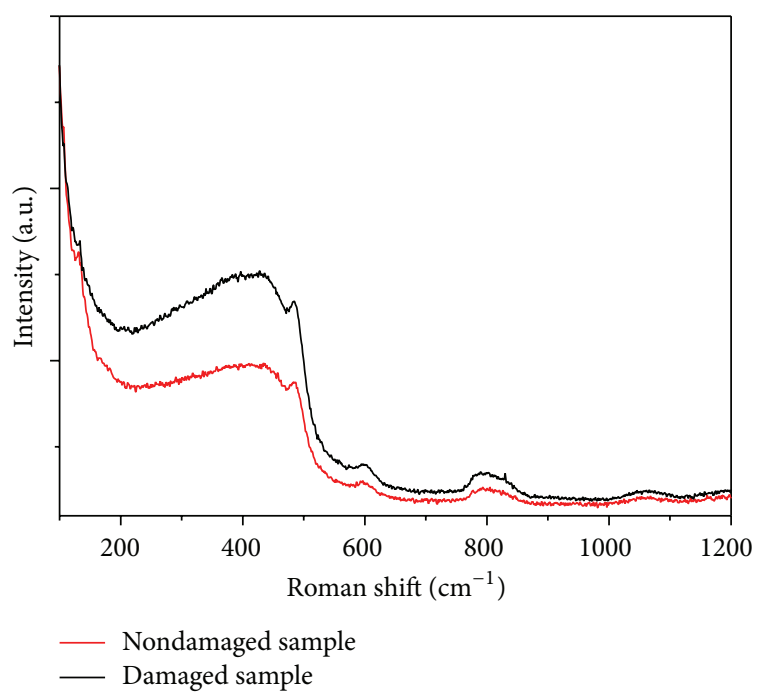

FIGURE 8: Typical Stokes Raman spectra of fused silica irradiated by UV laser beam with a fluence below LIDT (preirradiated and damage sample).

a series of broad bands, which reflect the coupled vibrational modes of the silica random network [37]. The main feature of this spectrum is the broad band centered at $430 \mathrm{~cm}^{-1}$ $\left(\omega_{1}\right)$. The frequency of this band relates to the $\mathrm{Si}-\mathrm{O}-\mathrm{Si}$ angle in the glass network, and its width is considered to reflect the width of Si-O-Si angle distribution [38]. Two relatively sharp bands $\left(D_{1}\right.$ and $\left.D_{2}\right)$ centered on $495\left(D_{1}\right)$ and 606 $\left(D_{2}\right) \mathrm{cm}^{-1}$, which may be assigned to in-phase breathing motions of oxygen atoms in puckered four- and planar three-membered ring structures, respectively [39]. Relative intensities of the $D_{1}$ and $D_{2}$ lines significantly increase in the damage sites (by $\sim 10 \%$ and $\sim 300 \%$ for $D_{1}$ and $D_{2}$ lines, resp.), which is related to the disruption of the continuous random network of $\mathrm{Si}-\mathrm{O}$ tetrahedral and to a densification of the material consistent with the recent Raman study of fused silica damaged with different laser pulses [40]. It is attributed to the change in ring statistics where sixfold rings transform to threefold and fourfold rings upon laser radiation [40]. This result is also consistent with previous reports on the densification of fused silica by X-ray, $\gamma$-ray, electron, ion, neutron, and so on [41], as well as by static compression and shock wave propagation [42]. The $\omega_{3}$ probably ascribes to a broad overtone band centered at about $803 \mathrm{~cm}^{-1}$ attributed to the $\mathrm{Si}-\mathrm{O}-\mathrm{Si}$ symmetric stretching mode. The Raman peak $\omega_{4}$ (attributed to the $\mathrm{Si}-\mathrm{O}-\mathrm{Si}$ asymmetric stretching mode) is about 1060 and $1194 \mathrm{~cm}^{-1}$ for TO and LO, respectively.

In absorption spectra, the absorbance of NBOHC increased with the laser power and/or number of laser pulses in vacuum. There are three FL bands of point defects in fused silica, which are assigned to the oxygen-related defects. The generation of point defects before the damage appeared is mainly due to that the UV irradiation can break the silicon oxygen bonds or the dangling bonds on the fused silica surface. However, there is a new band around $390 \mathrm{~nm}(3.1 \mathrm{eV})$ in the UV laser-induced damage crater. The origin of this

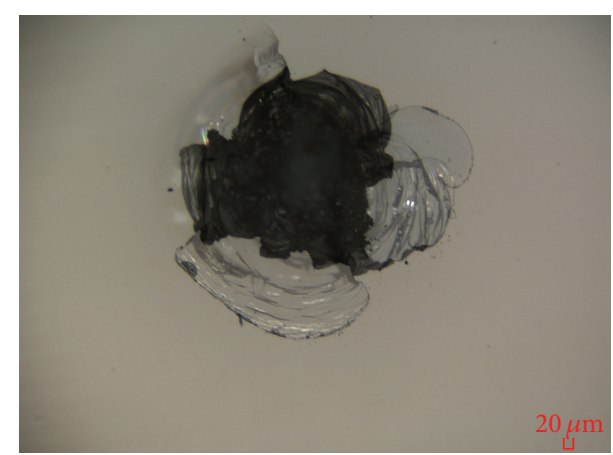

FIgURE 9: The optical micrographs of the damage sample.

band can be attributed to oxygen loss, typically accompanying rapid material heating and melting during laser-induced point defects. Furthermore, material densification revealed by Raman studies (Figure 8) is attributed to the shock-waveinduced densification and a rapid resolidification of the damage core. In the UV laser-induced damage crater of fused silica, the oxygen-deficient centers were detected as primary defects. Based on the above discussion, we can conclude that the condition of vacuum accelerates the formation process of laser-induced point defects and then produce laser-induced damage.

\section{Conclusion}

We have studied UV-vis, FL, and Raman scattering from fused silica preirradiated by UV laser with different laser pulse parameters in vacuum. Our results show that, after UV laser preirradiation in vacuum, the fused silica exhibits intense absorption or PL bands due to nonbridging oxygen hole centers, oxygen-deficiency defects, and some other laserinduced defects whose structure is presently unknown. Intensities of the absorption band and FL bands increase with laser power and/or number of laser pulses. Raman spectroscopy has revealed laser-induced material densification in samples. These results indicate the possibility that laser-induced point defects were introduced during the manufacturing process and enhanced by UV laser irradiation in vacuum. Further studies are currently needed to better understand these fundamental issues of defect formation on fused silica in different atmosphere, which is important for controlling the laser-induced damage in fused silica in many applications.

\section{Conflict of Interests}

The authors declare that there is no conflict of interests regarding the publication of this paper.

\section{Acknowledgment}

The authors acknowledge financial support from the National Natural Science Foundation of China (NSFC) under Grant no. 61078075 . 


\section{References}

[1] H. Zhang, Z. Yuan, J. Zhou, J. Dong, Y. Wei, and Q. Lou, "Laserinduced fluorescence of fused silica irradiated by ArF excimer laser," Journal of Applied Physics, vol. 110, no. 1, Article ID 013107, 2011.

[2] T. E. Tsai, D. L. Griscom, and E. J. Friebele, "Mechanism of intrinsic Si E-center photogeneration in high-purity silica," Physical Review Letters, vol. 61, no. 4, pp. 444-446, 1988.

[3] M. L. Andre, "Status of the LMJ project," in Solid State Lasers for Application to Inertial Confinement Fusion: Second Annual International Conference, vol. 3047 of Proceedings of SPIE, pp. 38-42, 1996.

[4] W. H. Lowdermilk, "Status of the National Ignition Facility Project," in Solid State Lasers for Application to Inertial Confinement Fusion: Second Annual International Conference, M. L. Andre, Ed., vol. 3047 of Proceedings of SPIE, Paris, France, October 1996.

[5] G. Pacchioni, L. Skuja, and D. L. Griscom, Eds. Kluwer Academic Publishers, Dordrecht, The Netherlands, 2000.

[6] J. W. Chan, T. Huser, S. Risbud, and D. M. Krol, "Structural changes in fused silica after exposure to focused femtosecond laser pulses," Optics Letters, vol. 26, no. 21, pp. 1726-1728, 2001.

[7] N. T. Nguyen, A. Saliminia, W. Liu, S. L. Chin, and R. Vallée, "Optical breakdown versus filamentation in fusedsilica by use of femtosecond infrared laser pulses," Optics Letters, vol. 28, pp. 1591-1593, 2003.

[8] D. C. Allan, C. Smith, N. F. Borrelli, and T. P. Seward III, "193nm excimer-laser-induced densification of fused silica," Optics Letters, vol. 21, no. 24, pp. 1960-1962, 1996.

[9] S. T. Yang, M. J. Matthews, S. Elhadj et al., "Comparing the use of mid-infrared versus far-infrared lasers for mitigating damage growth on fused silica," Applied Optics, vol. 49, no. 14, pp. 26062616, 2010.

[10] M. A. Stevens-Kalceff, A. Stesmans, and J. Wong, "Defects induced in fused silica by high fluence ultraviolet laser pulses at $355 \mathrm{~nm}$," Applied Physics Letters, vol. 80, no. 5, pp. 758-760, 2002.

[11] J. Wong, D. L. Haupt, J. H. Kinney et al., "Nature of damage in fused silica induced by high-fluence 3-omega 355-nm laser pulses, a multiscale morphology microstructure, and defect chemistry study," in Laser-Induced Damage in Optical Materials: 2000, 466, vol. 4347 of Proceedings of SPIE, Boulder, Colo, USA, October 2000.

[12] J. Wong, J. L. Ferriera, E. F. Lindsey, D. L. Haupt, I. D. Hutcheon, and J. H. Kinney, "Morphology and microstructure in fused silica induced by high fluence ultraviolet $3 \omega(355 \mathrm{~nm})$ laser pulses," Journal of Non-Crystalline Solids, vol. 352, no. 3, pp. 255272, 2006.

[13] M. D. Feit, A. M. Rubenchik, M. R. Kozlowski, F. Y. Genin, S. Schwartz, and L. M. Sheehan, "Extrapolation of damage test data to predict performance of large-area NIF optics at 355 nm," in Laser-Induced Damage in Optical Materials, vol. 3578 of Proceedings of SPIE, p. 226, SPIE, 1998.

[14] J. A. Menapace, B. Penetrante, D. Golini et al., vol. 4679 of Proceedings of SPIE, p. 56, SPIE.

[15] T. Kamimura, S. Akamatsu, M. Yamamoto et al., "Enhancement of surface-damage resistance by removing a subsurface damage in fused silica," in Laser-Induced Damage in Optical Materials, vol. 5273 of Proceedings of SPIE, pp. 244-249, September 2003.

[16] M. A. Norton, L. W. Hrubesh, Z. Wu et al., "Growth of laser initiated damage in fused silica at $351 \mathrm{~nm}$," in Laser-Induced
Damage in Optical Materials, vol. 4347 of Proceedings of SPIE, p. 468 , SPIE.

[17] R. A. Negres, M. W. Burke, S. B. Sutton, P. DeMange, M. D. Feit, and S. G. Demos, "Evaluation of UV absorption coefficient in laser-modified fused silica," Applied Physics Letters, vol. 90, no. 6, Article ID 061115, 2007.

[18] I. M. Burakov, N. M. Bulgakova, R. Stoian et al., "Spatial distribution of refractive index variations induced in bulk fused silica by single ultrashort and short laser pulses," Journal of Applied Physics, vol. 101, no. 4, Article ID 043506, 2007.

[19] M. Rothschild, D. J. Ehrlich, and D. C. Shaver, "Effects of excimer laser irradiation on the transmission, index of refraction, and density of ultraviolet grade fused silica," Applied Physics Letters, vol. 55, no. 13, pp. 1276-1278, 1989.

[20] H. Imai, K. Arai, H. Hosono, Y. Abe, T. Arai, and H. Imagawa, "Dependence of defects induced by excimer laser on intrinsic structural defects in synthetic silica glasses," Physical Review B, vol. 44, no. 10, pp. 4812-4818, 1991.

[21] M. A. Stevens Kalceff, "Cathodoluminescence microcharacterization of the defect structure of irradiated hydrated and anhydrous fused silicon dioxide," Physical Review B, vol. 57, no. 10, pp. 5674-5683, 1998.

[22] K. Ramseyer and J. Mullis, "Factors influencing short-lived blue cathodoluminescence of $\alpha$-quartz," The American Mineralogist, vol. 75, no. 7-8, pp. 791-800, 1990.

[23] M. Lancry, B. Poumellec, R. Desmarchelier, and B. Bourguignon, "Oriented creation of anisotropic defects by IR femtosecond laser scanning in silica," Optical Materials Express, vol. 2, no. 12, pp. 1809-1821, 2012.

[24] L. Vaccaro and M. Cannas, "Luminescence of the surface nonbridging oxygen hole center in silica: spectral and decay properties," Physical Review B, vol. 78, Article ID 075421, 2008.

[25] D. L. Griscom, "Optical properties and structure of defects in silica glass," Journal of the Ceramic Society of Japan, vol. 99, pp. 923-942, 1991.

[26] A. Anedda, C. M. Carbonaro, F. Clemente, R. Corpino, and P. C. Ricci, "Visible and ultraviolet emission of porous silica excited by synchrotron radiation," Journal of Non-Crystalline Solids, vol. 351, no. 21-23, pp. 1924-1927, 2005.

[27] L. N. Skuja, A. N. Trukhin, and A. E. Plaudis, "Luminescence in germanium-doped glassy $\mathrm{SiO}_{2}$," Physica Status Solidi A, vol. 84, no. 2, pp. K153-K157, 1984.

[28] M. A. Stevens-Kalceff and J. Wong, "Distribution of defects induced in fused silica by ultraviolet laser pulses before and after treatment with a $\mathrm{CO}_{2}$ laser," Journal of Applied Physics, vol. 97, no. 11, Article ID 113519, 2005.

[29] Y. Sakurai, "The $3.1 \mathrm{eV}$ photoluminescence band in oxygendeficient silica glass," Journal of Non-Crystalline Solids, vol. 271, no. 3, pp. 218-223, 2000.

[30] V. S. Kortov, A. F. Zatsepin, S. V. Gorbunov, and A. M. Murzakaev, "Luminescent defects in nanostructured silica," Physics of the Solid State, vol. 48, no. 7, pp. 1273-1279, 2006.

[31] S. Xu, X. Yuan, X. Zu et al., "Laser-induced defects in fused silica by UV laser irradiation," Journal of Non-Crystalline Solids, vol. 353, no. 44-46, pp. 4212-4217, 2007.

[32] A. E. Geissberger and F. L. Galeener, "Raman studies of vitreous $\mathrm{SiO}_{2}$ versus fictive temperature," Physical Review B, vol. 28, no. 6, pp. 3266-3271, 1983.

[33] R. J. Hemley, H. K. Mao, P. M. Bell, and B. O. Mysen, "Raman spectroscopy of $\mathrm{SiO}_{2}$ glass at high pressure," Physical Review Letters, vol. 57, no. 6, pp. 747-750, 1986. 
[34] J. W. Chan, T. R. Huser, S. H. Risbud, and D. M. Krol, "Modification of the fused silica glass network associated with waveguide fabrication using femtosecond laser pulses," Applied Physics A, vol. 76, no. 3, pp. 367-372, 2003.

[35] J. Z. Yang and X. Li, "Comparative study of boundary conditions for molecular dynamics simulations of solids at low temperature," Physical Review B, vol. 73, Article ID 224111, 2006.

[36] S. Xu, X. Zu, X. Jiang et al., "The damage mechanisms of fused silica irradiated by $355 \mathrm{~nm}$ laser in vacuum," Nuclear Instruments and Methods in Physics Research B: Beam Interactions with Materials and Atoms, vol. 266, no. 12-13, pp. 2936-2940, 2008.

[37] F. L. Galeener, A. J. Leadbetter, and M. W. Stringfellow, "Comparison of the neutron, Raman, and infrared vibrational spectra of vitreous $\mathrm{SiO}_{2}, \mathrm{GeO}_{2}$, and $\mathrm{BeF}_{2}$," Physical Review B, vol. 27, no. 2, pp. 1052-1078, 1983.

[38] F. L. Galeener and A. E. Geissberger, "Vibrational dynamics in ${ }^{30}$ Si-substituted vitreous $\mathrm{SiO}_{2}$," Physical Review B, vol. 27, no. 10, pp. 6199-6204, 1983.

[39] F. X. Liu, J. Y. Qian, X. L. Wang, L. Liu, and H. Ming, "UV irradiation-induced defect study of $\mathrm{GeO}_{2}-\mathrm{SiO}_{2}$ glasses by raman spectroscopy," Physical Review B, vol. 56, no. 6, pp. 30663071, 1997.

[40] R. E. Schenker and W. G. Oldham, "Ultraviolet-induced densification in fused silica," Journal of Applied Physics, vol. 82, no. 3, pp. 1065-1071, 1997.

[41] H. Sugiura, R. Ikeda, K. Kondo, and T. Yamadaya, "Densified silica glass after shock compression," Journal of Applied Physics, vol. 81, no. 4, pp. 1651-1655, 1997.

[42] L. Skuja, H. Hosono, and M. Hirano, "Laser-induced color centers in silica," in Laser-Induced Damage in Optical Materials, vol. 4347 of Proceedings of SPIE, pp. 155-168, October 2000. 

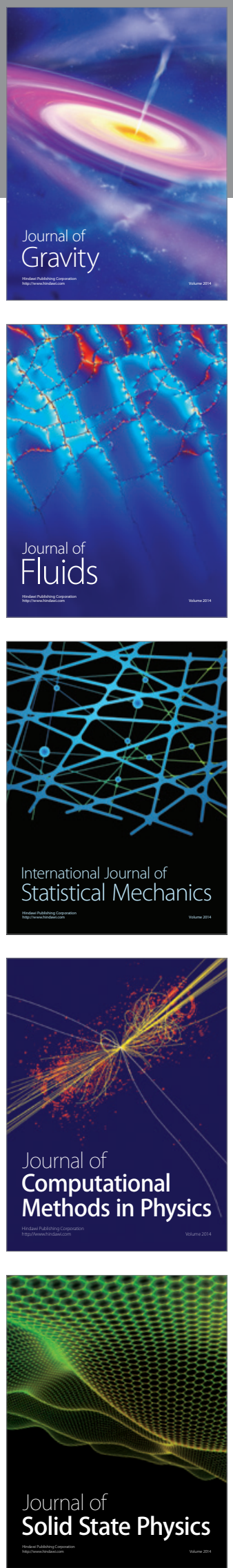

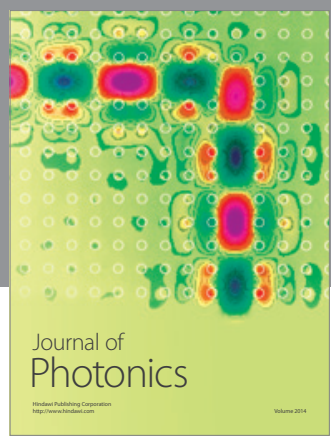

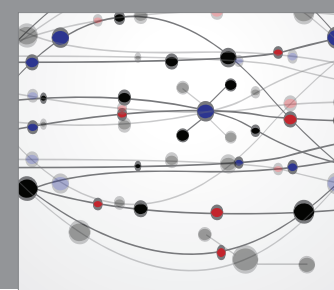

The Scientific World Journal

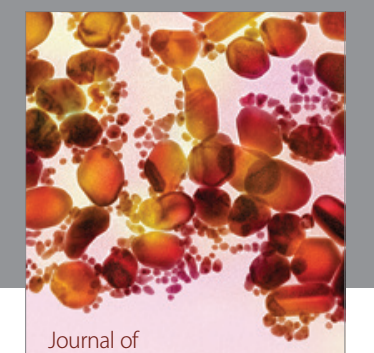

Soft Matter
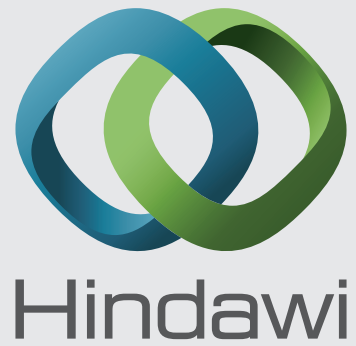

Submit your manuscripts at

http://www.hindawi.com
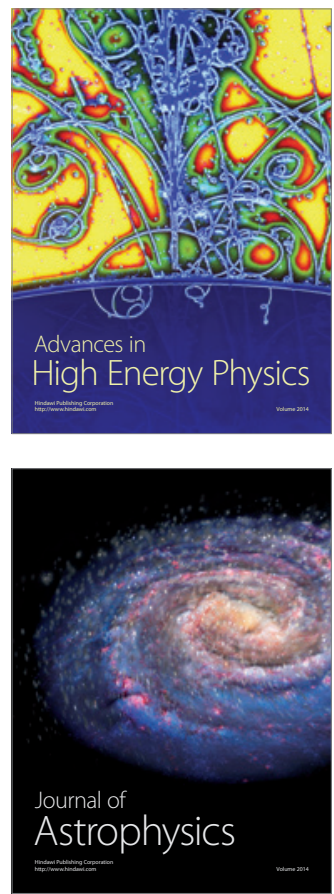
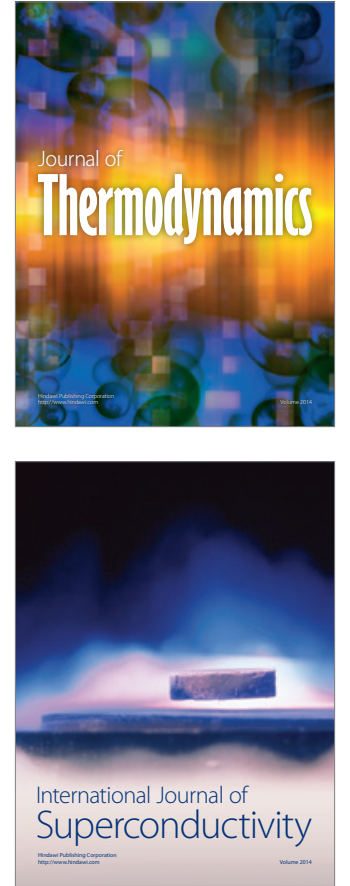
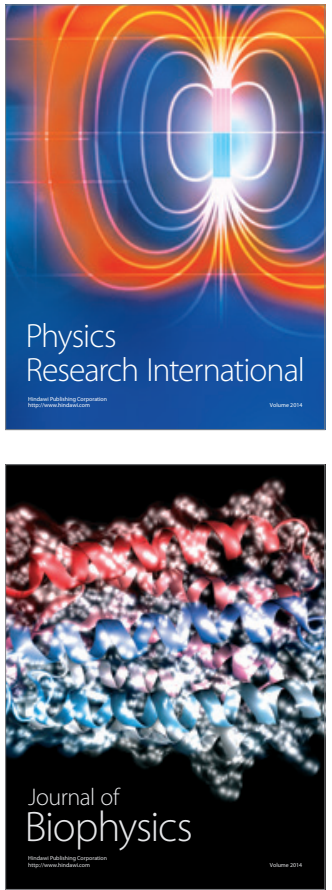
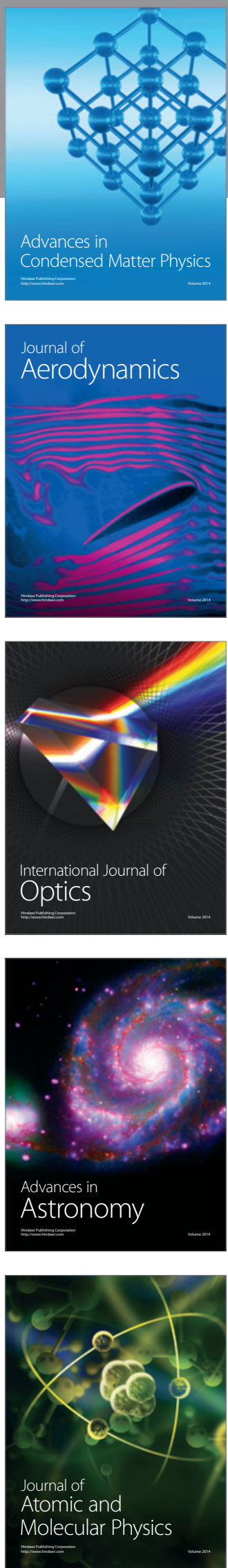